***Accepted for publication in the Journal of Environmental Studies and Sciences. Please refer to the journal for the final version of this article.

\title{
A Rooftop Revolution? A Multidisciplinary Analysis of State-Level Residential Solar Programs in New Jersey and Massachusetts
}

\author{
Alden Griffith \\ Assistant Professor \\ Environmental Studies Program \\ Wellesley College \\ Wellesley, MA 02481 \\ Monica Higgins \\ Visiting Lecturer \\ Environmental Studies Program \\ Wellesley College \\ Wellesley, MA 02481 \\ James Morton Turner [Corresponding Author] \\ Associate Professor \\ Environmental Studies Program \\ Wellesley College \\ Wellesley, MA 02481 \\ jturner@wellesley.edu \\ 781-283-2820
}

\begin{abstract}
The success of alternative energy policies is usually measured in terms of energy capacity. By this metric, statelevel policies to promote solar installations in New Jersey and Massachusetts have been a success. To fully evaluate these policies, however, it is necessary to consider how these policy programs are structured and funded, who participates in these programs, and the complete life-cycle consequences of 'clean' energy technologies. This paper focuses specifically on residential solar installations, which represent more than half of the total U.S. rooftop solar capacity potential. It takes a multidisciplinary approach that draws on policy analysis, spatial and demographic analyses, and life-cycle assessment. The analyses reveal three key conclusions: First, state-level policies have shifted from subsidies for solar installations to incentive-based support based on system performance, which have reduced the payback period for residential solar to less than ten years and have contributed to the growth of thirdparty leasing companies. Second, communities with low median income and/or a high percentage of non-white residents generally remain at lower than expected levels of participation. Third, while residential solar installations significantly offset greenhouse gas emissions and compounds that harm human respiratory health after 18 months, switching to photovoltaic panels generates a net increase in the production ecotoxic chemicals. Drawing on these observations we recommend policy changes to encourage broader geographic and demographic participation, to recognize the importance of solar leasing companies and landlords, and to promote the use of solar panels with lower environmental impacts across the lifecycle.
\end{abstract}




\section{Keywords}

GIS; Life-Cycle Analysis; Market-Based Incentives; Public Participation; Renewable Energy Policy; State-Level Policy.

\section{Introduction}

U.S. solar installations have surged since 2006, catalyzed by a combination of federal and state policies aimed at stimulating the alternative energy sector, contributing to economic growth, and mitigating greenhouse emissions. The U.S. has 7700 MW of installed solar capacity as of 2012, up from 330MW in 2006. And solar installations have been accelerating. In 2012, quarterly installations averaged over $800 \mathrm{MW}$, compared to $250 \mathrm{MW}$ per quarter in 2010. Residential solar installations are an important sector of the industry, and a growing number of homeowners are becoming renewable energy producers. Although residential installations accounted for only $20 \%$ of capacity in 2011, they account for $90 \%$ of the number of installations nationally (Sherwood 2012; Solar Energy Industries Association 2013). Moreover, more than half (53\%) of the estimated rooftop solar capacity in the U.S. is associated with residential buildings (Denholm and Margolis 2008).

State-level efforts to promote renewable energy have been a dynamic arena of policy innovation over the past decade, which has drawn the attention of scholars. Studies of state-level energy policies can be divided into two main categories: narrative case studies examining policy development in specific states (such as policies in California, New Jersey, or North Carolina) and comparative econometric evaluations of different policy strategies across states (such as the consequences of renewable energy portfolios versus energy efficiency standards) (Hart 2010; Gaul and Carley 2012; Frenkil and Yaffee 2012; Shrimali and Kniefel 2011; Shrimali et al. 2012). Most such studies, however, evaluate policy success largely in terms of total renewable energy capacity. But that approach discounts other potential metrics for evaluating policies, such as the distribution of renewable energy capacity, the demographics of participating residences, the cost, greenhouse gas mitigation, or the life-cycle environmental consequences of renewable energy policies.

This paper takes a multidisciplinary approach to examining these questions in the context of residential solar policies in two states: New Jersey and Massachusetts. It aims to address four questions: First, what are the structure and characteristics of the state-level policies that have contributed to the growth of residential solar installations in New Jersey and Massachusetts? Second, how has participation in these programs been affected by community-level demographic factors, such as income, race, or urbanization? Third, what are the net environmental costs and benefits of these state-level policies when considering the entire life cycle of solar installations? Finally, how do these factors interact, and what can we learn by examining them together? Our scope is initially focused here on residential solar installations for several reasons, one being the large potential for expanding residential solar energy 
capacity in the future. To advance that goal, it is necessary to evaluate issues concerning equity and access, which are central to efforts to expand participation in residential solar. Finally, residential production of solar energy represents a profound shift in the way energy is produced, and this analysis sheds light on social changes as well as matters directly associated with energy production.

\section{Incentivizing residential solar: A hybrid policy framework}

A multilayered policy framework underlies the growth in state-level solar installations that consists of subsidies, regulatory reforms, and incentives. Since 2006, the federal government has offered a $30 \%$ income tax credit for solar installations. Initially, the credit was capped at \$2000 and set to expire in 2008. Emergency legislation in response to the 2008 fiscal crisis removed the cap and extended the tax credit through 2016 (Database of State Incentives for Renewables \& Efficiency 2012). Although that credit is available nationally, growth in solar has been more rapid in states, such as New Jersey and Massachusetts, which have adopted additional state-level policies. Although such policies promote solar installations at utilities, commercial enterprises, and non-profit organizations, this paper focuses specifically on how these policies incentivize residential solar installations.

An important policy strategy has been an extensive system of state-level subsidies, which have been phased out in recent years in favor of performance-based incentives. Until 2008, New Jersey had a subsidy program to encourage solar installations, subsidizing residential installations at \$5.50 per watt in 2005 and \$3.50 per watt in 2007 (these subsidies accounted for $66 \%$ and $41 \%$ of the average installation costs, respectively), before phasing out subsidies due to cost overruns in 2008 (Hart 2010; Barbose, Darghouth, and Wiser 2012). Remaining subsidies in place in New Jersey include exemptions from sales tax and value-added property tax for installations (Hart 2010). Subsidies for residential solar installations are also declining in Massachusetts (Massachusetts Clean Energy Center 2013a). Such credits include a 15\% tax credit (capped at \$1000) against state income tax, exemptions from sales tax and value-added property tax for the solar installation, and a state-rebate program that subsidizes installations at a base level of $\$ 0.40$ per watt (plus an additional $\$ 0.40$ per watt for families earning less than $120 \%$ of the median income or owning homes of moderate value) capped at $\$ 4250$ per residential property (these subsidies accounted for $6 \%$ or 12\% of average 2011 installation costs, respectively) (Barbose, Darghouth; and Wiser 2012, DSIRE 2013a; Massachusetts Clean Energy Center 2013b).

Box 1. Renewable energy policy terminology

Renewable Energy Credit (REC): A credit awarded for the generation of $1000 \mathrm{kWh}$ of renewable energy (e.g. solar, wind, geothermal). In order to meet renewable energy targets, utilities must accumulate RECs through renewable energy production or by purchasing credits from others.

Renewable Portfolio Standard (RPS): A general policy tool that establishes minimum targets for 
renewable energy production from utilities. This is typically expressed as a percentage of total energy production by a certain date.

Solar Carve-Out: A minimum target specific to solar energy production as part of an existing RPS.

Solar Renewable Energy Credit (SREC): A $1000 \mathrm{kWh}$ renewable energy credit that is specific to the production of solar power.

The most innovative policy support for solar in New Jersey and Massachusetts has been the development of the market for Solar Renewable Energy Credits (SRECs; Box 1). Over the past 15 years, Renewable Portfolio Standards (RPS) have become a common policy tool for promoting renewable energy. RPS policies require utilities to source an expanding percentage of their electricity generation from renewable resources to meet a target percentage by a certain date. As of 2012, 29 states had renewable policy goals, including New Jersey $(22.5 \%$ renewable energy by 2021) and Massachusetts (15\% renewable energy by 2020) (Carley and Browne 2012). Although the structure of RPS vary across states, in most states utilities have flexibility in meeting the mandated RPS goals, including expanding renewable energy production or, alternatively, purchasing renewable energy credits ( $\mathrm{REC}=1000 \mathrm{kWh}$ generated from renewable sources) from other energy providers that have excess renewable energy capacity. Initially, most RPS were technology neutral and, as a result, the expansion in renewable energy generation favored least-cost technology. The outcome was a boom in wind power, which accounted for approximately $94 \%$ of the RPS-driven expansion in renewable energy capacity between 1998 and 2009 (Wiser, Barbose, and Holt 2011).

As a result, states took additional steps to structure RPS to foster a more diverse array of renewable energy technologies. As of 2013, sixteen states have adopted policies aimed at promoting solar power as part of their RPS, such as credit multipliers (giving additional credit to solar-sourced RECs compared to wind, for example) and solar carve-outs (establishing solar-specific RPS targets). In 2004, New Jersey established a solar carve-out goal of 2.1\% solar generation by 2021, which it increased in 2012 to 3.5\% by 2021 (DSIRE 2013a). In 2010, Massachusetts established a solar carve-out goal of 400MW by 2020 (DSIRE 2013b). In both states, utilities are required to secure sufficient solar renewable energy credits (SRECs $=1000 \mathrm{kWh}$ generated from solar) to meet the solar carve-out, whether it is through the direct production of solar energy or through the purchase of SRECs from others. SRECs usually sell for a price premium, compared to other RECs, due to the higher costs of solar installations. Such policies are justified as short-term support necessary to jumpstart the solar industry, realize economies of scale, and make solar competitive with other forms of energy production in the long-term.

Although New Jersey's and Massachusetts's policies are not identical, they have several features in common: 1) new solar installations are guaranteed participation in the state-wide SREC market for a significant period of time (15 years in New Jersey and 10 years in Massachusetts); 2) utilities must pay a fine for any shortfall in SREC compliance obligations, which is meant to help set a floor for SREC prices; and 3) SRECs must effectively be 
purchased from in-state sources (Bird, Heeter, and Creycik 2012). SRECs are a performance-based incentive, the price of which fluctuates with supply and demand on the market; prices have generally been falling as capacity has increased (SREC Trade 2013). These policies have driven a significant growth in residential solar capacity in New Jersey and Massachusetts, but at the cost of a significant investment of state funds in subsidies and utility payments for SRECs to meet the solar carve-out requirement (See Table 1).

Table 1. New Jersey and Massachusetts residential solar programs have been supported by state funding (rebates) and utility funding (SREC revenue), with the incentives shifting from subsidies to SRECs over time.

\begin{tabular}{|c|c|c|c|c|c|c|c|c|}
\hline \multirow[t]{2}{*}{ Year } & \multicolumn{4}{|c|}{ New Jersey Residential Solar } & \multicolumn{4}{|c|}{ Massachusetts Residential Solar } \\
\hline & $\begin{array}{l}\text { Annual } \\
\text { Capacity } \\
\text { Installed } \\
(\mathrm{kW})\end{array}$ & $\begin{array}{l}\text { Cumulative } \\
\text { Capacity } \\
\text { (kW) }\end{array}$ & $\begin{array}{l}\text { State } \\
\text { Rebates } \\
\text { (million } \\
\text { \$/year) }\end{array}$ & $\begin{array}{l}\text { SREC } \\
\text { Revenue } \\
\text { (million } \\
\$ / \text { year) }\end{array}$ & $\begin{array}{l}\text { Annual } \\
\text { Capacity } \\
\text { Installed } \\
(\mathrm{kW})\end{array}$ & $\begin{array}{l}\text { Cumulative } \\
\text { Capacity } \\
\text { (kW) }\end{array}$ & $\begin{array}{l}\text { State } \\
\text { Rebates } \\
\text { (million } \\
\text { \$/year) }\end{array}$ & $\begin{array}{l}\text { SREC } \\
\text { Revenue } \\
\text { (million } \\
\text { \$/year) }\end{array}$ \\
\hline 2004 & 1459 & 1459 & $\$ 7.82$ & $\mathrm{n} / \mathrm{a}$ & & & & \\
\hline 2005 & 3054 & 4513 & $\$ 16.46$ & $n / a$ & & & & \\
\hline 2006 & 6407 & 10,920 & $\$ 32.93$ & $\mathrm{n} / \mathrm{a}$ & & & & \\
\hline 2007 & 3540 & 14,461 & $\$ 16.87$ & $\$ 2.26$ & & & & \\
\hline 2008 & 5046 & 19,506 & $\$ 21.39$ & $\$ 3.58$ & & & & \\
\hline 2009 & 4574 & 24,080 & $\$ 14.66$ & $\$ 7.14$ & \multicolumn{4}{|c|}{ Massachusetts SREC Market Started in 2010} \\
\hline 2010 & 14,951 & 39,031 & $\$ 24.04$ & $\$ 11.12$ & 1724 & 1724 & $\$ 3.46$ & $\$ 0.20$ \\
\hline 2011 & 37,941 & 76,973 & $\$ 13.36$ & $\$ 19.19$ & 5839 & 7563 & $\$ 4.92$ & $\$ 2.10$ \\
\hline 2012 & 43,089 & 120,061 & $\$ 1.95$ & $\$ 29.28$ & 10,651 & 18,214 & $\$ 2.43$ & $\$ 4.30$ \\
\hline
\end{tabular}

\section{Who takes part in residential solar programs in New Jersey and Massachusetts?}

For residential homeowners, the economics of solar have improved over the past five years, in part because of federal and state policies, but also because of two related shifts in the solar industry. First, increased competition and advances in technology have lowered system costs from an average of approximately \$9 per installed watt in 2006 to approximately $\$ 6$ per installed watt in 2011 (these costs include solar panels, supporting infrastructure, and labor) (Barbose, Darghouth, and Wiser 2012). Second, third-party leasing companies have become significant players in the residential solar market in some states, including New Jersey and Massachusetts, offering 15- or 20-year leases to consumers with no down payments (while the companies generate a return on investment through lease payments, SREC revenue, and tax benefits). 
As a result, a homeowner installing an average-size residential solar array in Massachusetts (6kW) or New Jersey $(8 \mathrm{~kW})$ can expect to recoup the investment within seven or nine years, respectively, or, if leasing, to lower their monthly utility bill. For instance, an average-size residential installation in Massachusetts would cost $\$ 27,900$, less $\$ 8,370$ in federal tax rebates, $\$ 1,000$ in state tax rebates, and a $\$ 2,400$ state installation rebate, for a net cost of $\$ 16,130$. Such a system would generate two streams of revenue for a homeowner: first, cost savings from electricity generation (6300 kWh @ \$.16/kWh = \$1008 in year one); second, revenue from SREC sales (6 SRECs @ $\$ 200$ per SREC $=\$ 1200$ in year one). Alternatively, a homeowner could enter into a lease for approximately $\$ 75$ per month; in the first year, their cost savings would be $\$ 108$. Assuming energy costs and the lease payment increase at 3\% per year, 20-year savings would be $\$ 2900{ }^{1}$ (See Table 2)

Table 2. Economics of average solar installation in New Jersey and Massachusetts under current policies. Electricity savings based on average electricity rates in New Jersey and Massachusetts. SREC revenue based on average SREC market prices in 2012.

\begin{tabular}{lrr}
\hline & New Jersey & Massachusetts \\
\hline Average System Size & $8 \mathrm{~kW}$ & $6 \mathrm{~kW}$ \\
\hline Upfront Costs & & \\
\hline System Cost & $\$ 32,000$ & $\$ 27,900$ \\
Federal Tax Credit & $-\$ 9,600$ & $-\$ 8,370$ \\
State Tax Credit & & $-\$ 1,000$ \\
State Solar Rebate & & $-\$ 2,400$ \\
Net System Cost & $\$ 22,400$ & $\$ 16,130$ \\
\hline Annual Revenue & & \\
\hline Solar Generation (kWh) & 9600 & 6300 \\
Utility Savings (\$) & $\$ 1,639$ & $\$ 1,008$ \\
SREC Earnings (\$) & $\$ 900$ & $\$ 1,200$ \\
\hline Break Even (years) & 9 & 7 \\
\hline
\end{tabular}

Considering that the favorable economics for residential solar are a product of policies funded by the public (channeled through taxes and fees paid to the federal and state governments and customer payments to the electric utilities), it is important to consider who participates in these programs: is participation equitable across region, race,

\footnotetext{
${ }^{1}$ Lease pricing for average systems in Massachusetts and New Jersey acquired from Sungevity.com, February
} $28,2013$. 
and income? This question becomes more relevant, considering the potential for significant expansion of rooftop residential solar energy capacity, relative to other installations (such as commercial, governmental, or utility) (Denholm and Margolis 2008). To examine this question, we analyzed participation in residential solar programs in New Jersey and Massachusetts. In both cases, the states release quarterly databases of solar installations qualified to generate SRECs, including information such as installation date, location (zip code), system size, and system cost. As a result, our analysis of solar program participation was aggregated at the zip code scale and normalized based on the number of detached single-family dwelling units. The results allow for examination of which types of communities are more or less likely to have households participating in residential solar (See Online Resource 1 for detailed methodologies).

Overall, participation is generally low, but geographically widespread, in both states, with $96 \%$ and $82 \%$ of zip codes in New Jersey and Massachusetts respectively having some participation and $37 \%$ and $10 \%$ of zip codes in New Jersey and Massachusetts respectively having greater than $1 \%$ of detached single-unit homes participating. When analyzed for geographic clustering of high and low values (Figure 1), it becomes evident that participation tends to be lower in urban areas, such as zip codes near Camden and Newark in New Jersey and Worcester and Springfield in Massachusetts. In part, this may be because these are low-income or minority zip codes, which tend to have lower participation as explained below. It is also important to point out that these spatial patterns emerge when home ownership is accounted for, which could otherwise be a driver of urban-rural differences. The exception to this trend is Boston and surrounding suburbs, which has participated in the Solarize Mass program (see below), and since 2009 has participated in Renew Boston, a city-wide program to promote energy efficiency and alternative energy programs, including additional support for residential solar (such as a city-level solar rebate subsidy matching the state subsidies since 2011) (City of Boston 2011).
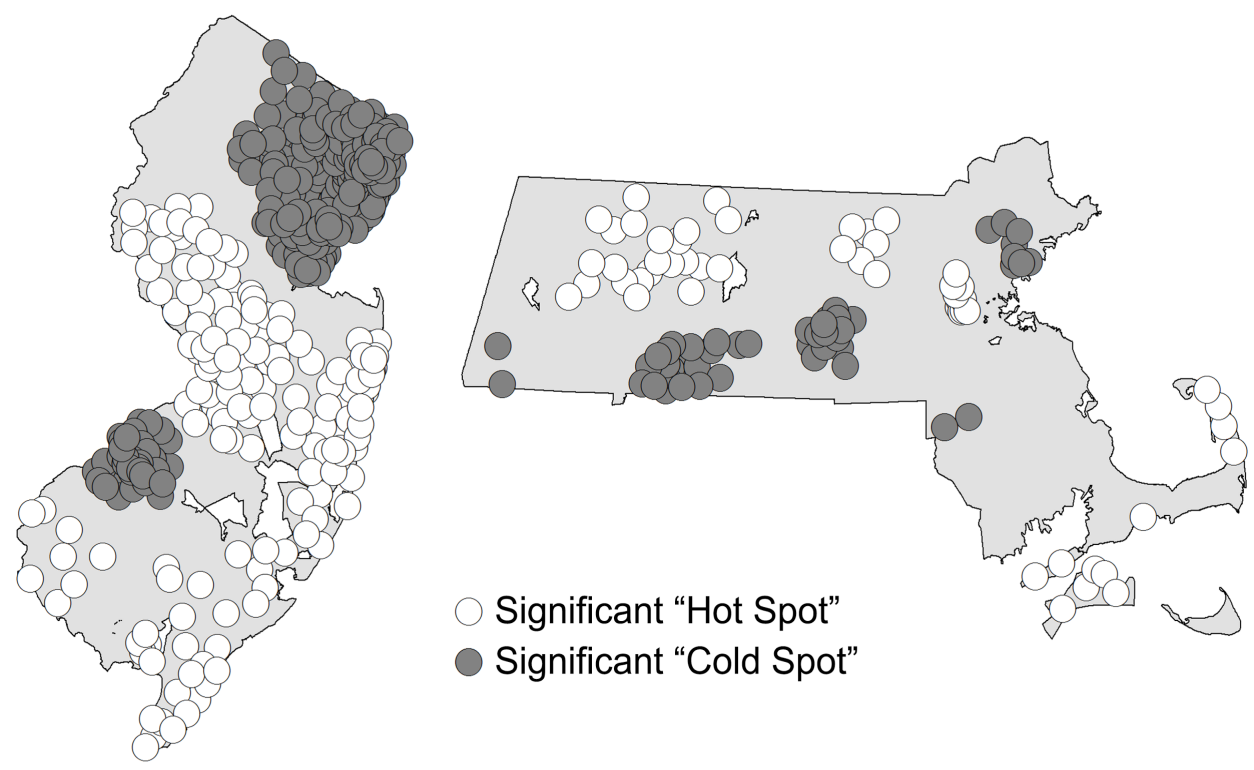
Fig. 1 Hot spot analysis of residential solar installations per owned single-unit household. Each point represents a zip code that has disproportionately high ("hot spot") or low ("cold spot") residential solar installations within a neighborhood radius (14 km for MA, $20 \mathrm{~km}$ for NJ). A threshold of $P<0.05$ was used to determine statistical significance. Note that individual zip codes labeled "hot" or "cold" do not necessarily have high or low participation themselves - it is their neighborhood radius that is considered.

In order to examine how participation varies across important demographic factors, we conducted randomization tests to compare observed median participation values to a null distribution (Fig. 2, see Online Resource 1 for methodology. Online Resource 2 provides an additional regression analysis). The most striking result regarding income is the low level of participation in the lowest median income quintile. It appears that relationships between participation and income are driven by lower income brackets more so than by a continuous trend across the income distribution. This is not surprising, considering that residents of the lowest median income quintile are least likely to have capital funds to invest in solar or credit scores necessary to qualify for a third-party solar lease. Notably, this trend is consistent in both New Jersey and Massachusetts. Although Massachusetts doubles the solar subsidy for moderate income homeowners or moderate-value properties (27\% of installations have received that rebate), that has apparently not resulted in more even participation across lower income brackets.
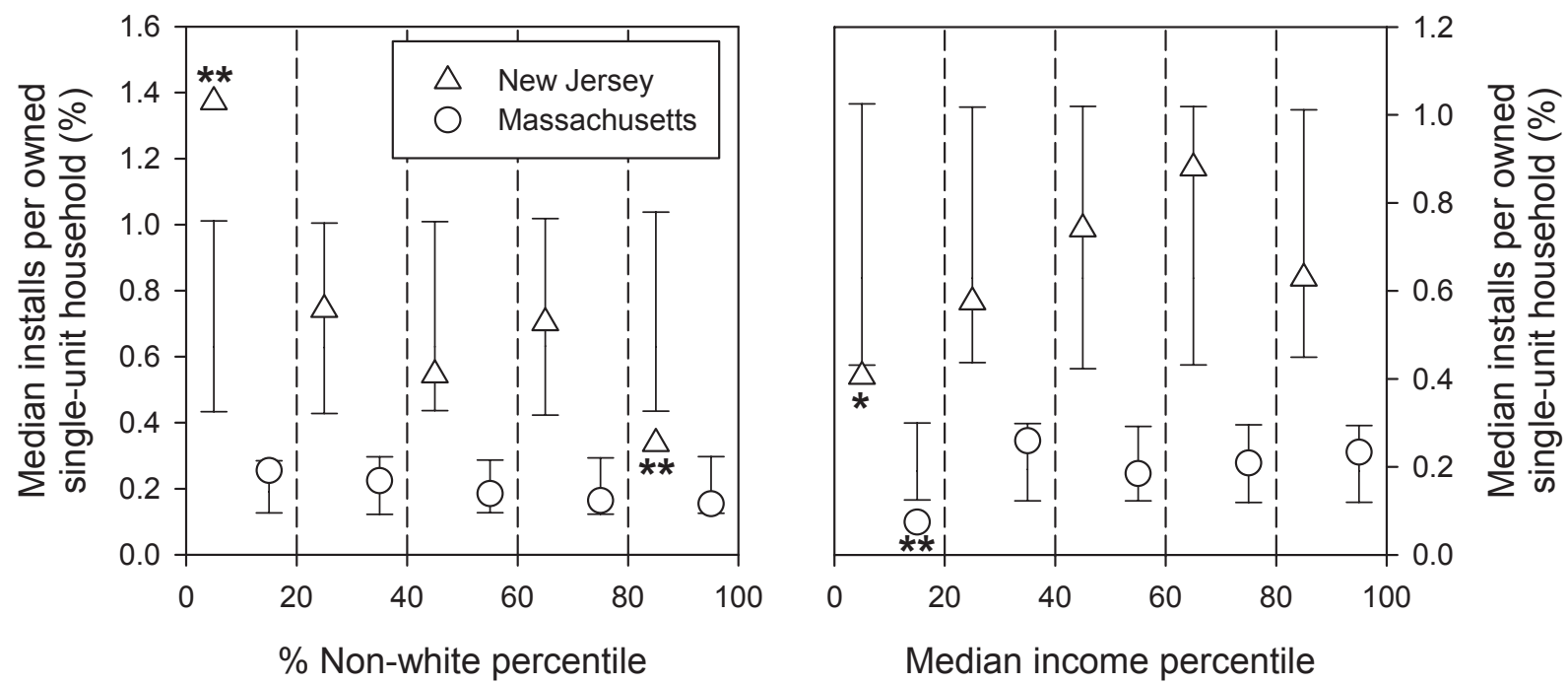

Fig. 2 Comparison of observed values of median solar program participation for within-state demographic quintiles to randomized (null) distributions. Error bars represent the 99.9th percentile of the null distribution from 10,000 iterations (a conservative approach was taken due to the presence of spatial autocorrelation). $* 1$ out of 10,000 iterations more extreme than observed value. ${ }^{* *} 0$ out of 10,000 iterations more extreme than observed value. 
Similar to income, the racial composition of zip codes appears to be a contributing, but not straightforward, factor in participation in residential solar programs. In New Jersey there is a strong trend of decreasing participation as the racial diversity of the zip code increases (in both regressions and randomization tests). However, New Jersey is also a more diverse state, with a median of $21.4 \%$ non-white residents across zip codes compared to $8.4 \%$ in Massachusetts. Another complicating factor is the relationship between racial diversity and median income in these states (i.e. both independent variables). For both states, low-minority zip codes (below the median value for percent non-white residents) exhibit no relationship between race and income. However, in high-minority zip codes, income decreases as the percentage of non-white residents increases, making it difficult to tease apart income and race.

Notably, though, in both New Jersey and Massachusetts, participation in non-white communities shows a distinct temporal trend: participation in more diverse communities lags that of whiter communities (Fig. 3). This indicates that although whiter communities are early adopters, the diversity of participants has increased as the programs have become established.

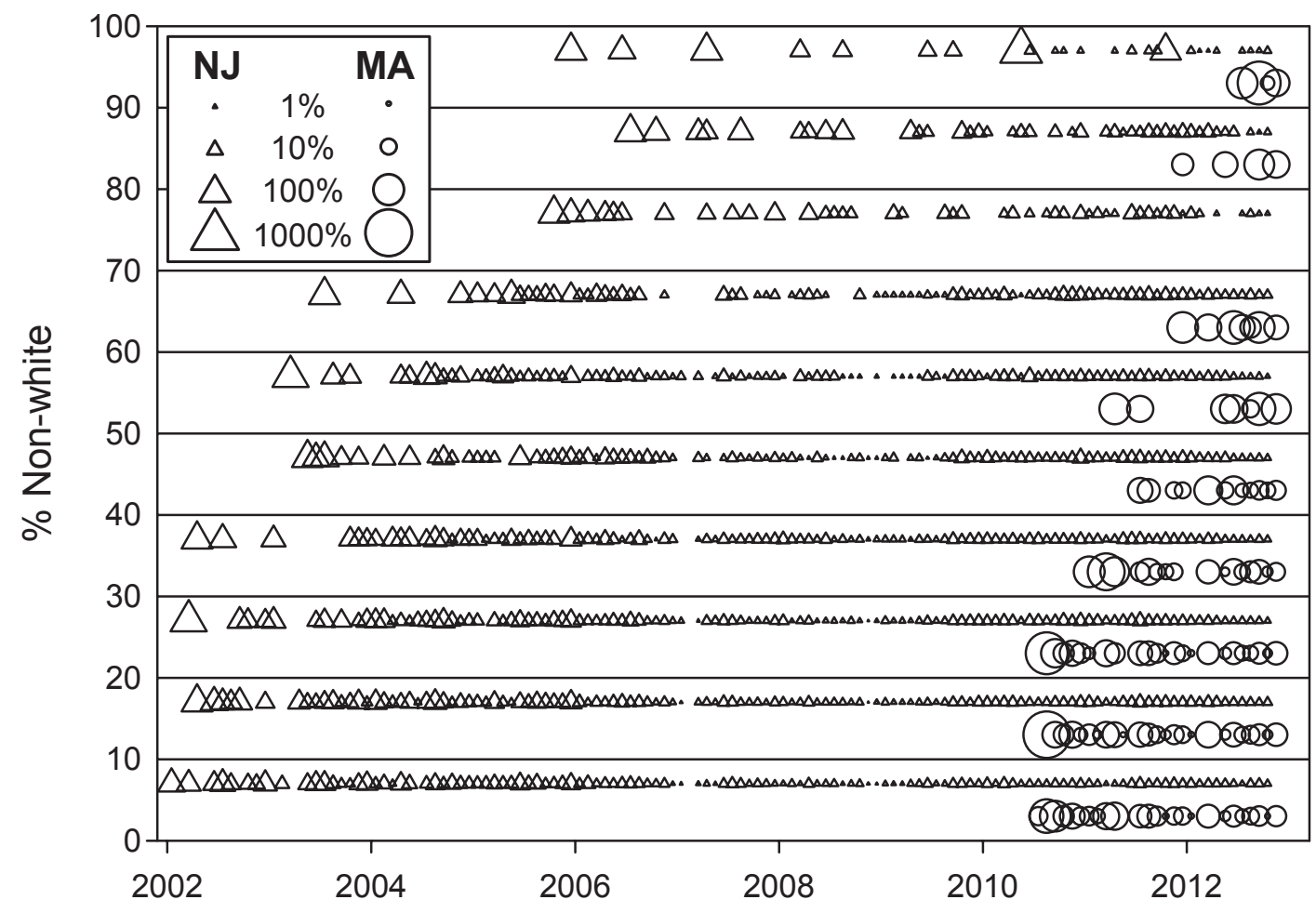

Fig. 3 Month-to-month growth rates (\%) in total residential solar installations according to the percentage of non-white residents. Installations were pooled across zip codes within each bin and growth rates were used in order to compare changes in program participation through time regardless of total participation values. 


\section{How does residential solar affect the environment?}

Residential solar is described, both at the state- and consumer-level, as an important step toward reducing greenhouse gas emissions to address climate change. For instance, when Massachusetts passed the enabling legislation for a solar carve-out in 2008, the governor described the legislation as positioning Massachusetts as a leader "in reducing the emissions that threaten the planet with climate change" ("Governor Patrick" 2008). And residential solar installations provide customers with real-time updates on how much carbon dioxide their system has mitigated, measured in tons, equivalent car miles, or trees. As Sungevity.com explains to its customers: "Congratulations! Since going solar, you've offset $x$ lbs of carbon emissions." or "You have planted the equivalent of $x$ trees."

But such analyses only consider the use-phase consequences of residential solar, not the life-cycle consequences of residential solar. Nor do such analyses consider the human health or environmental impacts that are not associated with global climate change. To consider the life-cycle consequences of residential solar, both at the state level and the residential installation, we conducted a life cycle assessment (LCA) considering the manufacture, installation, and use phases using a hybrid LCA methodology and present impact results in categories addressing climate change, human health, and ecosystem health. Our approach, unlike LCAs focused on single installations under general conditions, considers the impact of the average residential solar installation in each state and the cumulative impact of solar installations under these policies, based on the average solar insolation in these states (See Online Resources 1 for detailed methodologies).

The environmental impact of each life cycle stage was modeled based on available system capacity and cost information along with process-based (manufacturing and use phases) and economic input-output (installation) databases. Sourcing materials for and manufacturing the panels releases trace amounts of metals, such as aluminum, zinc, and copper, which make up a majority of the human health noncancer (HHN) and ecotoxicity potential (ETP) impacts (see Figure OR3-5 in Online Resources 3). Installing panels requires inputs from economic sectors including power generation and supply, truck transportation, and oil and gas extraction, which contribute significantly to the global warming potential (GWP) and human health respiratory (HHR) categories. During the use-phase, solar panels generate clean electricity with no associated emissions, offsetting US grid electricity and emissions that contribute to GWP and HHR categories. The overall life-cycle impact compares the use-phase environmental benefits of solar installations against the environmental burdens of manufacturing and installation, as seen in Table 3. 
Table 3. Life cycle assessment results for New Jersey and Massachusetts solar policies. LCA results based on installation rate growth of 5\% quarterly and 20-year panel lifetime.

\begin{tabular}{lcrrrr}
\hline \multicolumn{1}{c}{ New Jersey } \\
\hline \multicolumn{1}{c}{ Impact Category } & Units & Manufacture & Installation & Grid Offset & Life Cycle \\
Global Warming Potential & mt CO - eq & $1,487,824$ & 884,183 & $40,680,668$ & $-38,308,660$ \\
Human Health Noncancer & mt Toluene-eq & $72,556,688$ & 65,998 & $71,199,085$ & $1,423,602$ \\
Human Health Respiratory & mt PM2.5-eq & 1,639 & 1,890 & 66,873 & $-63,343$ \\
Ecotoxicity Potential & mt 2,4-D-eq & $4,595,674$ & 50 & $1,449,008$ & $3,146,715$ \\
\hline \multicolumn{1}{c}{ Impact Category } & Units & Massachusetts & & & \\
\hline Global Warming Potential & mt CO -eq & 330,311 & 197,396 & $8,254,186$ & $-7,726,478$ \\
Human Health Noncancer & mt Toluene-eq & $16,155,324$ & 14,613 & $14,429,892$ & $1,740,046$ \\
\hline Human Health Respiratory & mt PM2.5-eq & 363 & 417 & 13,548 & $-12,769$ \\
Ecotoxicity Potential & mt 2,4-D-eq & $1,024,060$ & 11 & 293,702 & 730,369 \\
\hline
\end{tabular}

To assess the environmental consequences of each state's solar policy, we modeled solar installations in New Jersey and Massachusetts, assuming installation targets of $1800 \mathrm{MW}$ in New Jersey and $400 \mathrm{MW}$ in Massachusetts, installation rates growing at $5 \%$ annually, and a conservative 20 -year lifetime for individual solar installations. Not surprisingly, significant reductions are observed in GWP, with life-cycle reductions being at least 15 times greater than the consequences of manufacturing and installing systems. This reduction is the result of the GWP offset obtained by displacing US grid electricity, which was modeled at an emission rate of $775.99 \mathrm{~g} \mathrm{CO}_{2} / \mathrm{kWh}$. Based on a twenty-year lifetime, the emission rates were $49.81 \pm 11.12$ and $54.82 \pm 11.70 \mathrm{~g} \mathrm{CO}_{2} / \mathrm{kWh}$ for the average installation in New Jersey and Massachusetts, respectively. These values are within the range presented in metalevel analyses of solar installations (National Renewable Energy Laboratory 2013) (see Online Resource 3) and confirm that publicizing the reductions in greenhouse gas emissions is justified.

When a broader range of environmental impacts is considered, however, the solar policies in New Jersey and Massachusetts are responsible for both environmental benefits and burdens. Reductions in HHR are more than 15 times greater than manufacturing and installation burdens due to the high offset from grid electricity (and, especially, coal-fired electricity generation in the US grid fuel mix). In HHN, the burdens introduced in manufacturing and installation are essentially offset by the reduction required grid electricity. In ETP, however, the life-cycle impact value is positive, meaning the policies had a net negative impact on the environment; the high ecotoxicity of manufacturing is not significantly offset by the reduction in generation of electricity based on the US grid fuel mix. Overall, the results of this analysis suggest that there are significant environmental benefits from statewide solar policies in terms of GWP and HHR, but that those benefits come at the cost of an increase in ETP (Figure 4). 


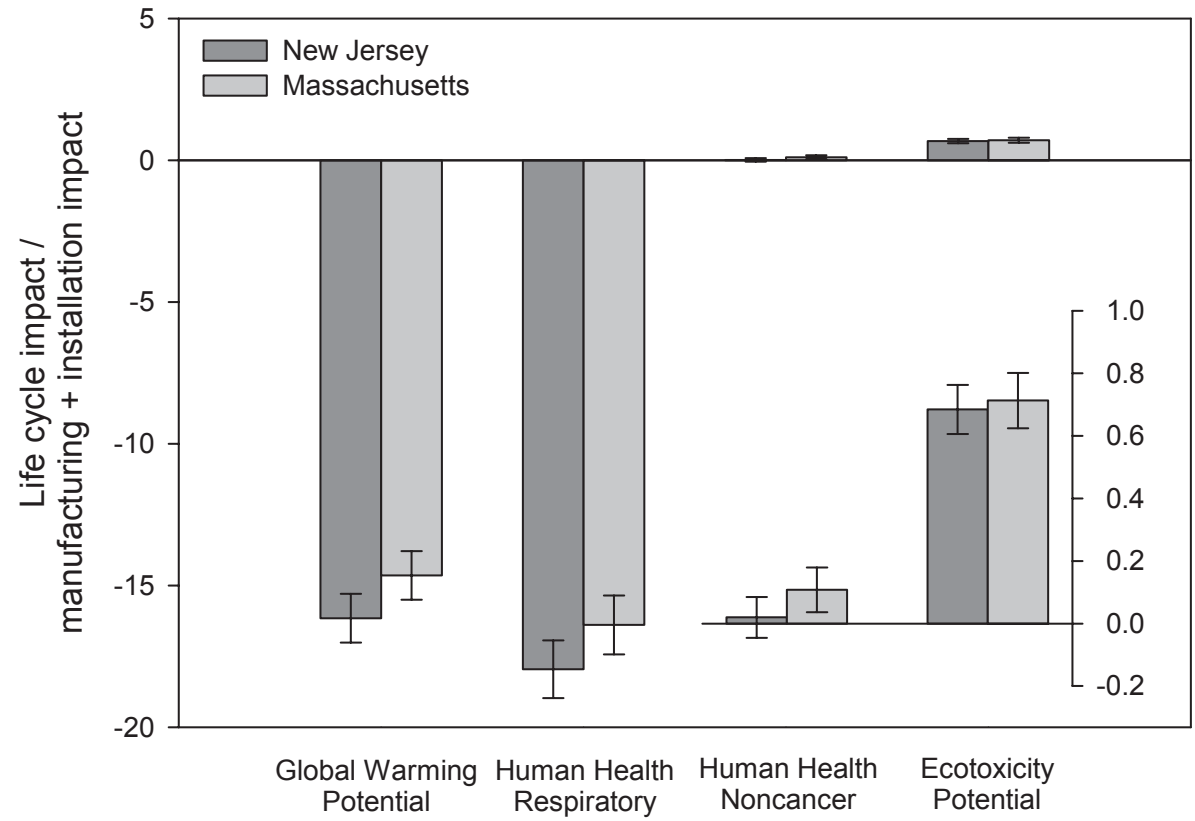

Fig 4. Projected life cycle impacts normalized as a fraction of the total manufacturing and installation impacts assuming $5 \%$ quarterly growth in added capacity and a 20 year solar panel lifetime. Error bars represented standard deviations from Monte Carlo analysis $(n=1000)$. Negative values indicate a net environmental benefit (offset) of solar panel installations, which are primarily a result of reductions in emissions from the U.S. grid

Just as homeowners consider the financial payback period of installing a solar array, they could also consider an environmental payback period, or the number of years to recoup the environmental investment of manufacturing and installing their solar array (Table 4). For the average residential installation, environmental benefits are significant in both GWP and HHR and the environmental break-even point is one to two years. But, those benefits come with greater contributions to HHN and ETP associated with manufacturing the panels, with break-even points of twentyfour and seventy-three years respectively (See Online Resource 3).

Table 4. Breakeven analysis for New Jersey and Massachusetts homeowners. Values represent the number of years required for an average-sized residential installation to offset the associated construction and installation impacts.

\begin{tabular}{llcc}
\hline \multicolumn{1}{c}{ Impact Category } & \multicolumn{1}{c}{ Units } & $\begin{array}{c}\text { New Jersey } \\
\text { Breakeven Years }\end{array}$ & $\begin{array}{c}\text { Massachusetts } \\
\text { Breakeven Years }\end{array}$ \\
\hline Global Warming Potential & mt CO -eq & 1.3 & 1.4 \\
Human Health Noncancer & mt Toluene-eq & 23.5 & 25.7 \\
Human Health Respiratory & mt PM2.5-eq & 1.1 & 1.2 \\
Ecotoxicity Potential & mt 2,4-D-eq & 72.9 & 80.3 \\
\hline
\end{tabular}




\section{Conclusion and synthesis}

To date, the majority of renewable solar capacity has been installed at commercial, governmental, utility, and other non-residential facilities. As of 2011, residential installations only accounted for $20 \%$ of installed solar capacity, although $53 \%$ of the potential rooftop solar capacity in the U.S. is associated with residential buildings. If the full potential of solar renewable energy is going to be realized, it will be necessary to significantly expand residential installations (Denholm and Margolis 2008; Sherwood 2012; Solar Energy Industries Association 2013).

An important goal of this study is to integrate multiple factors in order to more comprehensively evaluate policies promoting residential solar power. Unlike most studies, which focus on metrics such as total solar capacity and usephase greenhouse gas mitigation, this study gives explicit consideration to other spatial and temporal factors. Although these policies generally apply uniformly at the state or federal level, their outcomes are hardly uniform in space and time. Through time we see changes in state-level support for solar that have facilitated a shift from direct purchases by homeowners to an increasing role of third party lessors, substantially different break-even time horizons depending on how the environmental impacts of solar power are considered, and delayed participation by more racially diverse communities. Through space we see geographic patterns across both states that highlight a lack of participation in urban areas associated with high-minority and/or low-income communities, and the potential for spatial disconnects between the environmental benefits (use-phase) and costs (manufacturing) of solar power. Drawing on these observations, we recommend new policy strategies and avenues for research regarding the relationship between the social, economic, and life-cycle consequences of state-level residential solar policies.

First, considering the structure of state-level policies in connection with the spatial and demographic analyses of the resulting residential solar installations reveals ways in which these programs could be improved to reach a broader array of state residents. Even when accounting for home ownership, existing solar policies in these states have resulted in disproportionately low participation in low-income and high-minority communities. This is surprising in Massachusetts, which provides additional subsidies for moderate- and low-income households. In order to utilize the full solar capacity of residential buildings, it is necessary to ensure widespread participation and long-term citizen support. This requires policy changes that will better target state-level solar programs in low-income and more diverse communities.

There are several ways in which state-level policies could be altered to encourage broader participation. Currently, incentives targeting moderate income families or moderate home value properties in Massachusetts are limited to resident-purchased installations and are not applicable to the growing solar leasing industry. Extending such meansbased subsidies to third-party leasing companies and landlords, for installations on moderate income properties, could expand participation by further incentivizing installations in underrepresented communities. Such policy changes could make such installations more profitable or make leases less expensive. In addition, Massachusetts has begun actively targeting specific communities through its Solarize Mass program, which partners towns with 
installers and encourages solar installations through tiered discounts based on participation levels (as more residents participate, installers commit to reduced pricing). Currently, this program has targeted communities that can "demonstrate local interest and engagement," which has prevented it from significantly expanding the demographic base of solar installations (Massachusetts Clean Energy Center 2013c). Altering existing policies in Massachusetts to prioritize under-represented communities, or creating them in New Jersey, could broaden public support for and contribute to the long-term viability of renewable energy policy.

Second, considering these policies in connection with the life-cycle analysis of solar installations reveals ways in which policies could be improved to further encourage environmental sustainability. Current solar energy policies are most often described as promoting the renewable energy sector and mitigating greenhouse gas emissions that contribute to climate change. Considering the life-cycle of residential solar installations, both at the scale of the individual homeowner and at the scale of state-level policies, extends and complicates that description. Residential solar panels result in significant decreases not only in greenhouse gas emissions, but equally significant reductions in human-health respiratory illnesses due to overall reductions in emissions from fossil fuel-based power plants. Considering recent research which suggests that some of the most compelling arguments for addressing climate change focus on human health, giving more attention to the near-term positive consequences such policies can have on respiratory health could further expand support for such renewable energy policies (Maibach et al., 2010).

But any simple claim that these policies advance 'clean' energy ignores the consequences for ecosystem toxicity. Installing solar in Massachusetts or New Jersey mitigates greenhouse gas emissions and respiratory illness, but results in increased ecotoxicity burdens further up the supply chain, where materials are mined, refined, and panels manufactured. These increases in ecotoxicity potential have a distinct geography, which is determined by the supply chain and manufacturing processes underlying the solar panel industry. Such impacts differ dramatically by the type of panel and by panel manufacturer, however. (Figure OR3-6; Silicon Valley Toxics Coalition 2013). If Massachusetts and New Jersey aim to advance sustainable clean energy, policies should encourage the installation of solar panels that minimize life-cycle environmental impacts. Currently, Massachusetts encourages the installation of Massachusetts-manufactured solar panels with a $\$ .05 /$ watt subsidy. A similar subsidy, based on the environmental performance of panel manufacturers as determined by a third-party certifier could incentivize the installation of lower-impact solar panels (Silicon Valley Toxics Coalition 2013).

This study advances analysis of the residential solar sector and the policies that promote it in the United States. It also suggests avenues for future research. An important development in state solar markets has been the rise of third-party leasing options. As data become available, investigating the different demographics of owner-purchased and leased systems will be important. Although New Jersey and Massachusetts have emerged as the leaders of residential solar installations in the eastern United States, other states have been pursuing similar programs with varied results. How do policies in Massachusetts and New Jersey compare with similar policies, such as the SREC markets adopted in Maryland and Ohio, which have been less effective in spurring solar installations? Other states, 
such as California and Arizona, have successfully scaled up solar installations without relying on similar marketbased incentives. Do such alternative policy models affect the demography and geography of residential installations? Lastly, although this paper focuses specifically on the residential sector, it would be worth pursuing similar analyes regarding the geography of other solar installations, such as residential, commercial, and governmental installations.

\section{References}

Barbose, G., N. Darghouth, and R. Wiser. (2012, November). Tracking the Sun V: An Historical Summary of the Installation of Photovoltaics in the United States, 1998-2011. Retrieved from: http://emp.lbl.gov/sites/all/files/lbnl-5919e.pdf

Bird L., J. Heeter, and C. Creycik. (2012). Solar Renewable Energy Certificate (SREC) Markets: Status and Trends. (Boulder, CO: National Renewable Energy Laboratory). Retrieved from: http://nrelpubs.nrel.gov/WebtopSecure/ws/nich/int/nrel/Record?rpp=25\&upp=0\&m=1\&w=NATIVE\%28\% 27KEYWORD2+ph+words $+\% 27 \% 27 \mathrm{srec} \% 27 \% 27 \% 27 \% 29 \&$ order $=$ native $\% 28 \% 27$ pubyear $\% 2 \mathrm{FDescend}$ $\% 27 \% 29$

Carley, S. and T. R. Browne. (2012). Innovative US Energy Policy: A Review of States' Policy Experiences. Wiley Interdisciplinary Reviews: Energy and Environment. Retrieved from: http://onlinelibrary.wiley.com/doi/10.1002/wene.58/full

City of Boston. (2011, June 21). Mayor Menino Announces New Residential Solar Program to Help Residents go Green [Press Release]. Retrieved from: http://www.cityofboston.gov/news/default.aspx?id=5159

Database of State Incentives for Renewables \& Efficiency. (2012). Residential Renewable Energy Tax Credit. Retrieved from: http://dsireusa.org/incentives/incentive.cfm?Incentive_Code=US37F

Database of State Incentives for Renewables \& Efficiency. (2013a). New Jersey: Renewable Portfolio Standard. Retrieved from: http://www.dsireusa.org/incentives/incentive.cfm?Incentive_Code=NJ05R

Database of State Incentives for Renewables \& Efficiency. (2013b). Commonwealth Solar II Rebates. Retrieved from: http://www.dsireusa.org/incentives/incentive.cfm?Incentive Code $=\mathrm{MA} 71 \mathrm{~F} \& \mathrm{re}=0 \& \mathrm{ee}=0$

Denholm, P. and R. Margolis. (2008). Supply Curves for Rooftop Solar PV-Generated Electricity for the United States. National Renewable Energy Laboratory Technical Report. NREL/TP-6A0-44073.

Frenkil, D. J. and D. P. Yaffe. (2012). Renewable Energy Certificates: a Patchwork Approach to Deploying Clean Technologies. The Journal of World Energy Law \& Business 5, 1-12.

Gaul, C. and S. Carley. (2012). Solar Set Asides and Renewable Electricity Certificates: Early Lessons from North Carolina's Experience with Its Renewable Portfolio Standard. Energy Policy. 48, 460-469.

Governor Patrick Signs Bills to Create Green Jobs and Reduce Emissions [Press Release]. (August 2008). Retrieved from: http://www.mass.gov/governor/pressoffice/pressreleases/2008/governor-patrick-signs-bills-to-creategreen.html

Hart, D. M. (2010). Making, breaking, and (partially) remaking markets: State regulation and photovoltaic electricity in New Jersey. Energy Policy. 38, 6662-6673.

Maibach, E.W., M. Nisbet, P. Baldwin, K. Akerlof, and G. Diao. (2010). Reframing Climate Change As a Public Health Issue: An Exploratory Study of Public Reactions. 10, 299. Retrieved from:

http://www.biomedcentral.com/1471-2458/10/299 
Massachusetts Clean Energy Center. (2013a). Commonwealth Solar Summary Report. Retrieved from: http://masscec.com/index.cfm/pk/download/id/13039/pid/11151

Massachusetts Clean Energy Center. (2013b). Commonwealth Solar II Photovoltaic Rebate Program: Program Manual. Retrieved from: http://www.masscec.com/masscec/file/REG/CommSolar/block14/CSII_Program\%20Manual_V14_FINAL. pdf

Massachusetts Clean Energy Center. (2013c). 2013 Round 2 Solarize Massachusetts Community RFP. Retrieved from: http://www.masscec.com/solicitations/2013-round-2-solarize-massachusetts-community-rfp

National Renewable Energy Laboratory. (2013). "Life Cycle Greenhouse Gas Emissions from Solar Photovoltaics." Retrieved from: http://www.nrel.gov/docs/fy13osti/56487.pdf

Sherwood, L. (2012, August), U.S. Solar Market Trends 2011. Retrieved from: http://www.irecusa.org/wpcontent/uploads/IRECSolarMarketTrends-2012-Web-8-28-12.pdf

Shrimali, G. and J. Kniefel. Are Government Policies Effective in Promoting Deployment of Renewable Electricity Resources? Energy Policy 39, 4726-4741.

Shrimali, G., S. Jenner, F. Groba, G. Chan, and J. Indvik. Have State Renewable Portfolio Standards Really Worked? Synthesizing Past Policy Assessments to Build an Integrated Econometric Analysis of RPS Effectiveness in the US. No 1258, Discussion Papers of DIW Berlin, DIW Berlin, German Institute for Economic Research.

Silicon Valley Toxics Coalition. (2013). 2013 Solar Scorecard. Retrieved from: http://www.solarscorecard.com/2013/2013-SVTC-Solar-Scorecard.pdf

Solar Energy Industries Association. (2013). Solar energy Facts: 2012 Year-In-Review. Retrieved from: http://www.seia.org/sites/default/files/Q4\%20SMI\%20Fact\%20Sheet\%20FINAL.pdf

SREC Trade. (2013). SREC Market Prices. Retrieved from: http://www.srectrade.com/srec_prices.php

Wiser, R., G. Barbose, and E. Holt. (2011). Supporting solar power in renewables portfolio standards. Energy Policy 39, 3894-3905. 
Online Resources 1: Detailed methodologies

A Rooftop Revolution? A Multidisciplinary Analysis of State-Level Residential Solar Programs in New Jersey and Massachusetts

Journal of Environmental Studies and Sciences

\section{1 - Methodologies for analysis of residential subsidies and SREC revenue}

To determine the financial support for residential solar through subsidy programs, subsidies for residential installations were extracted from the following databases of solar installations and subsidy programs in New Jersey and Massachusetts:

New Jersey Clean Energy Program, Updated Project Status List as of December 31, 2012:

http://www.njcleanenergy.com/files/file/Renewable_Programs/CG\%20Updates\%20/CG/October\%20201 2/REIP_Approved_Projects_103112.xls

Commonwealth Solar Installers, Costs, Etc. as of December 31, 2012:

http://www.masscec.com/index.cfm/page/Downloads-and-Resources/pid/11163

There were two steps to estimate the revenue for residential solar through SREC programs. First, the total SREC revenue (which was estimated based on records of SRECs generated for the year and the average selling price of SRECs during the year) was determined using the following information sources. Second, the share of total SREC revenue accounted for by residential installations was assigned based on the percentage of cumulative state capacity accounted for by residential installations.

New Jersey Clean Energy Program, SREC Pricing:

http://www.njcleanenergy.com/renewable-energy/project-activity-reports/srec-pricing/srec-pricing

Massachusetts Energy and Environmental Affairs, Current Status of the Solar Carve-Out Program, SRECs Minted and Expected:

http://www.mass.gov/eea/energy-utilities-clean-tech/renewable-energy/solar/rps-solar-carve-out/srectable.xlsx 


\section{$\underline{2 \text { - Methodologies for demographic and geospatial analyses }}$}

\section{Data Sources}

For the spatial and demographic analyses, several datasets were combined at the zip-code level. Solar energy program participation data were obtained from New Jersey's Clean Energy Program (http://www.njcleanenergy.com/renewable-energy/project-activity-reports/installation-summarytechnology/installation-summary-technology) and the Massachusetts Office of Energy and Environmental Affairs (http://www.mass.gov/eea/energy-utilities-clean-tech/renewable-energy/solar/rps-solar-carve-out). These datasets contained all individual solar installations through October 2012 that participated in state incentive programs. We then calculated the number of residential installations and total residential capacity $(\mathrm{kW})$ for each zip code.

We used demographic data from the 2007-2011 American Community Survey (ACS; US Census Bureau, released December 6, 2012), which is the first ACS dataset to include values by Zip Code Tabulation Areas (ZCTAs). ZCTAs are very similar to US Postal Service (USPS) zip codes, but they do not necessarily share the exact same geographic boundaries. This is in part because USPS zip code boundaries can slightly change over time, and may not even represent geographical areas (e.g. a single building can have its own zip code). Although the USPS zip code geographies for solar energy data do not always line up perfectly with the ACS ZCTA geographies, their disagreements are minor compared to the scale of our overall analysis, and we consider any possible impact to be negligible.

Demographic and solar installation data were joined to ZCTA geographies using ArcMap (Version 10.0, Environmental Systems Resource Institute). Zip codes with a total area of less than $0.1 \mathrm{~km}^{2}$ were excluded from analyses (25 in MA and 19 in NJ). The vast majority of these were small portions of a zip code from neighboring states that happened to cross into the target state outlines that were used as clipping geographies. Others were nonresidential zip codes such as Boston city hall and a medical center. We also excluded zip codes ( 7 in MA and 9 in NJ) with populations less than 50 (most were less than 20) as we felt that participation in solar energy programs could not be robustly resolved. The total number of zip codes included in the analyses were 513 in MA and 575 in NJ.

Our main questions were related to residential participation in state solar energy programs, and thus our main response variable was the number of residential solar installations per zip code normalized by the number of owneroccupied, single-unit households (expressed as a percent). This is a more appropriate normalizing factor than the total number of households, as participation in solar programs is assumed to be largely impossible for renters and apartment owners. Our main independent variables were median household income and the percentage of non-white residents. 


\section{Hotspot Analysis}

We used hotspot analysis to examine spatial clustering of solar energy program participation within each state (ArcMap Version 10.0, Environmental Systems Resource Institute). Analyses were performed using Euclidean distances, with neighborhood distance bands of $14 \mathrm{~km}$ for MA and $20 \mathrm{~km}$ for NJ. The distances were chosen as a compromise between making sure that all points had enough neighbors and maintaining a small enough scale to detect regional differences. Significant clustering of high (hot) or low (cold) solar installation participation values were determined using the Getis-Ord Gi* statistic with significance level of $\alpha=0.05$.

\section{Linear Regression}

We initially examined the relationships between solar installation participation and demographics in each state by regressing zip code participation against both median household income and the percentage of non-white residents (JMP, Version 9, SAS Institute Inc.). Box-Cox transformations were applied to all variables to adjust for skewness in the data (participation $\lambda=0.33$, income $\lambda=0.32, \%$ non-white $\lambda=0.37$ ), although only median household income could be considered to be robustly characterized by a normal distribution (both solar installation participation and $\%$ non-white residents contained many zero values). We accounted for spatial autocorrelation in the calculation of statistical significance by calculating effective sample sizes using SAM (Spatial Analysis in Macroecology, Version 4.0; Rangel et al., 2010) and adjusting $F$ tests accordingly. For example, the regression of solar installation participation against \% non-white residents in $\mathrm{NJ}$ had an original sample size of $\mathrm{n}=575$ and an effective sample size of $n=64.53$ once spatial autocorrelation was accounted for. After adjusting the degrees of freedom, this reduced the $F$ statistic from 51.8 to 5.65 to account for lack of independence among data points. We also examined the regressions using solar installation participation normalized by all households to examine the potential participation barrier imposed by lack of home ownership.

\section{Randomization Tests}

We also performed randomization tests to examine the relationship between solar installation participation and demographics (Matlab, Version R2012b, Mathworks, Inc.). Our objective was to examine participation in different income and minority brackets (as opposed to assuming a linear relationship), and to avoid assumptions of normally distributed data. For each iteration of the test, values of solar installation participation were randomly paired with values of median income or $\%$ non-white residents. 10,000 iterations were performed and the randomized median participation values for each income or minority quintile were compared to the observed median participation values. As there was no readily apparent means to account for spatial autocorrelation using this method, we adopted a conservative approach and only considered highly significant results (e.g. $\leq 1$ permutation out of 10,000 that is more extreme than the observed value, which corresponds to a two-tailed $P$ value $\leq 0.0002$ ). 


\section{$\underline{3 \text { - Methodologies for Environmental Impact Assessment }}$}

The life cycle assessment was conducted in accordance with the ISO 14040 standard, though neither an internal or external critical review by LCA professionals was conducted. SimaPro life cycle assessment software was used to conduct the LCA (Version 7.1, PRe' Consultants bv). Inventory data were obtained from the US LCI and Ecoinvent Life Cycle Inventory databases for process-based LCI for solar panels and electricity generation. The economic input-output LCA (EIO-LCA) database (Carnegie Mellon University Green Design Institute 2008) was used to quantify installation impacts. Monte-Carlo analysis was run using Matlab software for uncertainty analysis (Version 2012a, Mathworks, Inc.).

\section{Goal and Scope}

The goal of the analysis was to examine the life-cycle environmental impacts of both the Massachusetts and New Jersey residential solar programs and to evaluate the programs' respective environmental consequences across a range of impact categories. The scope of the study included manufacture of solar panels, installation of solar panels on homes or businesses, and a twenty-year operating phase for each panel installed.

\section{Functional Unit}

This analysis presents results for three related functional units, based on the installed capacity of solar in either Massachusetts or New Jersey. The first unit is the total solar capacity in MW of all the residential solar projects operating in either state under the initiatives from the beginning of records to an ending date of 10/31/2012 (132 MW in Massachusetts and 918 MW in New Jersey). A second functional unit is based on the stated total capacity goal of each initiative, $400 \mathrm{MW}$ in Massachusetts and $1800 \mathrm{MW}$ in New Jersey. The third and final function unit is an average residential installation PV generating capacity in each state, $6.9 \mathrm{~kW}$ in Massachusetts and $8.1 \mathrm{~kW}$ in New Jersey.

\section{Inventory Data Sources and Calculations}

Data on solar installations in Massachusetts and New Jersey was accessible on the internet through state databases (the same databases that were used in the geospatial and demographic analyses). In Massachusetts, projects were listed with capacities, total costs, and program enrollment dates. Total cost data was not available for New Jersey projects. Data were organized into quarterly added capacity and quarterly total capacity, which were used for analysis. Capacity reporting was assumed to be correct and was not analyzed during uncertainty analysis.

\section{Uncertainty Analysis}

All of the values needed for life cycle assessment were obtained from the publicly available capacity information published by Massachusetts and New Jersey. To examine the uncertainty introduced into the analysis by calculation steps, a number of parameters were introduced and a Monte-Carlo analysis was run with 1000 iterations. Additional 
iterations did not produce significantly different results, as there were only five variables and all were uniformly distributed.

Peak Sun Parameter. Energy production was obtained from capacity information by applying the peak sun hours for each state and the number of days in operation. Peak sun in Massachusetts was allowed to vary uniformly between 2.99 and 4.27 hours/day. In New Jersey, peak sun was uniformly distributed between 3.2 and 4.76 hours/day.

Cost-Capacity Parameter. The relationship between cost and capacity was determined using the entirety of Massachusetts projects, with the average being $\$ 5.95 /$ watt with a standard deviation of $\$ 1.78 /$ watt. Using this value, the cost of installations in Massachusetts and New Jersey were estimated from the quarterly added capacity.

Installation Cost Parameter. The installation cost was assumed to be uniformly distributed between 5 and $25 \%$ of the total system cost.

Cost-Area Parameter. The relationship between cost and panel area was determined by surveying commerciallyavailable solar panels online. The value obtained was $6.6 \mathrm{~m}^{2} / \mathrm{kW}$. As this was highly unknown, the value of the capacity-area parameter was allowed to vary between 3 and $9 \mathrm{~m}^{2} / \mathrm{kW}$.

Multi-Si Parameter. A solar panel composite, representing the market share of single-Si, multi-Si, and ribbon-Si panels was constructed. Ribbon panels were maintained at $10 \%$ of total market share, or $10 \%$ of the total area installed. The area of the multi-Si panel was assigned a uniform distribution between $25 \%$ and $55 \%$ of the total area. The balance of $100 \%$ was made up with single-Si Panels.

Table OR1-2. Summary of Uncertainty Parameters

\begin{tabular}{|l|l|l|l|}
\hline Parameter & Distribution & High & Low \\
\hline Peak Sun Parameter [MA] & Uniform & 4.27 hours/day & 2.99 hours/day \\
\hline Peak Sun Parameter [NJ] & Uniform & 4.76 hours/day & 3.2 hours/day \\
\hline Cost-Capacity Parameter & Uniform & $\$ 7.738 /$ Watt & $\$ 4.176 /$ Watt \\
\hline Installation Cost Parameter & Uniform & 0.20 & 0.05 \\
\hline Area-Capacity Parameter & Uniform & $3 \mathrm{~m}^{2} / \mathrm{Watt}$ & $9 \mathrm{~m}^{2} / \mathrm{Watt}$ \\
\hline Multi-Si Panel Parameter & Uniform & $0.25 \mathrm{~m}^{2} / \mathrm{m}^{2}$ & $0.55 \mathrm{~m}^{2} / \mathrm{m}^{2}$ \\
\hline
\end{tabular}


Impact Assessment

Life Cycle Impact Assessment was carried out with the TRACI II Impact Assessment methodology, developed by the US EPA (Bare et al., 2003). Results of the Inventory Analysis where characterized using TRACI factors to four impact categories: Global Warming Potential [ $\mathrm{kg} \mathrm{CO}_{2}$ eq.], Noncarcinogenics [kg Toluene-eq.], Human Health Respiratory Effects [kg PM2.5-eq.], and Ecotoxicity [kg 2,4-D-eq.]. These categories were chosen because they were deemed representative of general trends and for their specific usefulness in assessing the issue of solargenerated electricity.

\section{References for Methodologies}

Carnegie Mellon University Green Design Institute. (2008) Economic Input-Output Life Cycle Assessment (EIOLCA), US 1997 Industry Benchmark model. http://www.eiolca.net. Accessed 1 January, 2008.

Bare, J. C.; Norris, G. A.; Pennington, D. W.; McKone, T. (2003). TRACI: The tool for the reduction and assessment of chemical and other environmental impacts. J Ind Ecol 6, 49-78.

Rangel, T.F.; Diniz-Filho, J.A.F. and Bini, L.M. (2010). SAM: A comprehensive application for Spatial Analysis in Macroecology. Ecography 33, 1-5. 
Online Resources 2: Linear regressions of solar program participation and demographic factors

A Rooftop Revolution? A Multidisciplinary Analysis of State-Level Residential Solar Programs in New Jersey and Massachusetts

Journal of Environmental Studies and Sciences

In addition to the randomization tests presented in the text, we also used linear regression to examine relationships between participation and zip code demographics (Online Resource 1). The advantages of linear regression are that continuous relationships may be identified rather than discrete differences among quintiles, and that issues of spatial autocorrelation and statistical significance can be more directly addressed. Disadvantages include the inability to satisfy assumptions of normally-distributed data (including many zero values), and the assumption that all relationships are linear across the entire range of values.

Our analysis revealed some trends with respect to race and income, but amid substantial variability. Notably, participation significantly decreases with increasing percentage of non-white residents in New Jersey, and participation significantly increases with increasing median income in Massachusetts. Additionally, changes in the slope of the relationships when participation included all households (not just homeowners) were consistent with the idea that lack of home ownership is a barrier to participation in solar energy programs; looking at all households reduced participation in low-income zip codes and in zip codes with a high percentage of non-white residents. This is consistent with strong correlations between these demographic factors and the percentage of households that are renting. 

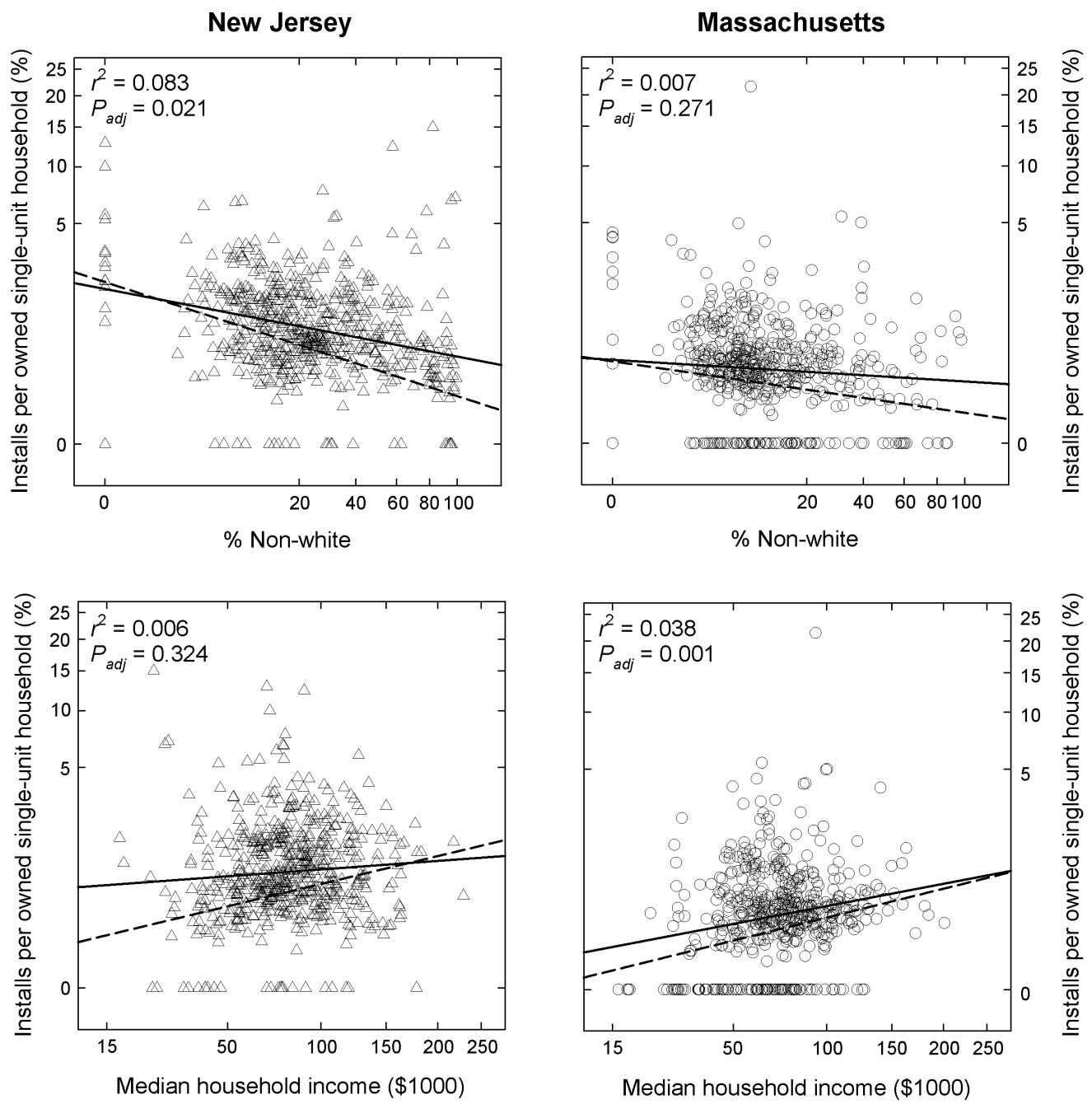

Figure OR2-1. Linear regressions of zip code residential solar energy participation and demographic factors. All values are Box-Cox transformed and $P$ values are adjusted for spatial autocorrelation. Dashed lines are the regression using all households as the normalizing factor; the wedge that is produced between both regression lines is indicative of the "participation barrier" due to home ownership. 
Online Resource 3: Additional life cycle environmental impact results

A Rooftop Revolution? A Multidisciplinary Analysis of State-Level Residential Solar Programs in New Jersey and Massachusetts

Journal of Environmental Studies and Sciences

\section{Contents}

1. Comparison of solar policy results with operation of $100 \mathrm{MW}$ coal-fired power plant

2. Comparison of this study with NREL Meta-Level Solar Impact Analysis

3. Life cycle impacts for an average homeowner

4. Contribution analysis of solar panel ecotoxicity

\section{Comparison of solar policy results with operation of $100 \mathrm{MW}$ coal-fired power plant}

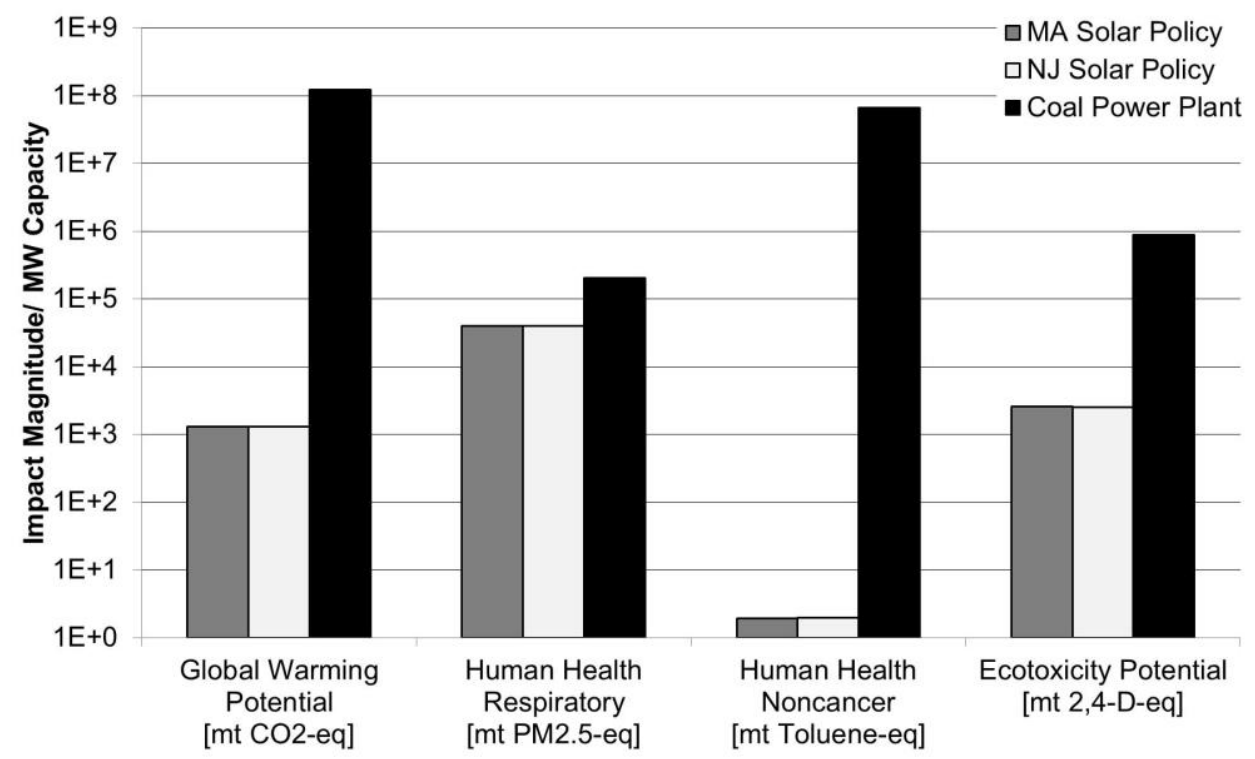

Figure OR3-1. Comparison of environmental impact magnitudes for MA and NJ solar policies with $100 \mathrm{MW}$ coal-fired power plant. 
To determine whether modeling assumptions made in this study were consistent with other life cycle assessments of solar panels and solar installations, we compared the systems in this study with the results presented in the NREL Solar Impact Analysis. In order to compare with the NREL analysis, we adopted the assumed lifetime of thirty years used in the NREL.

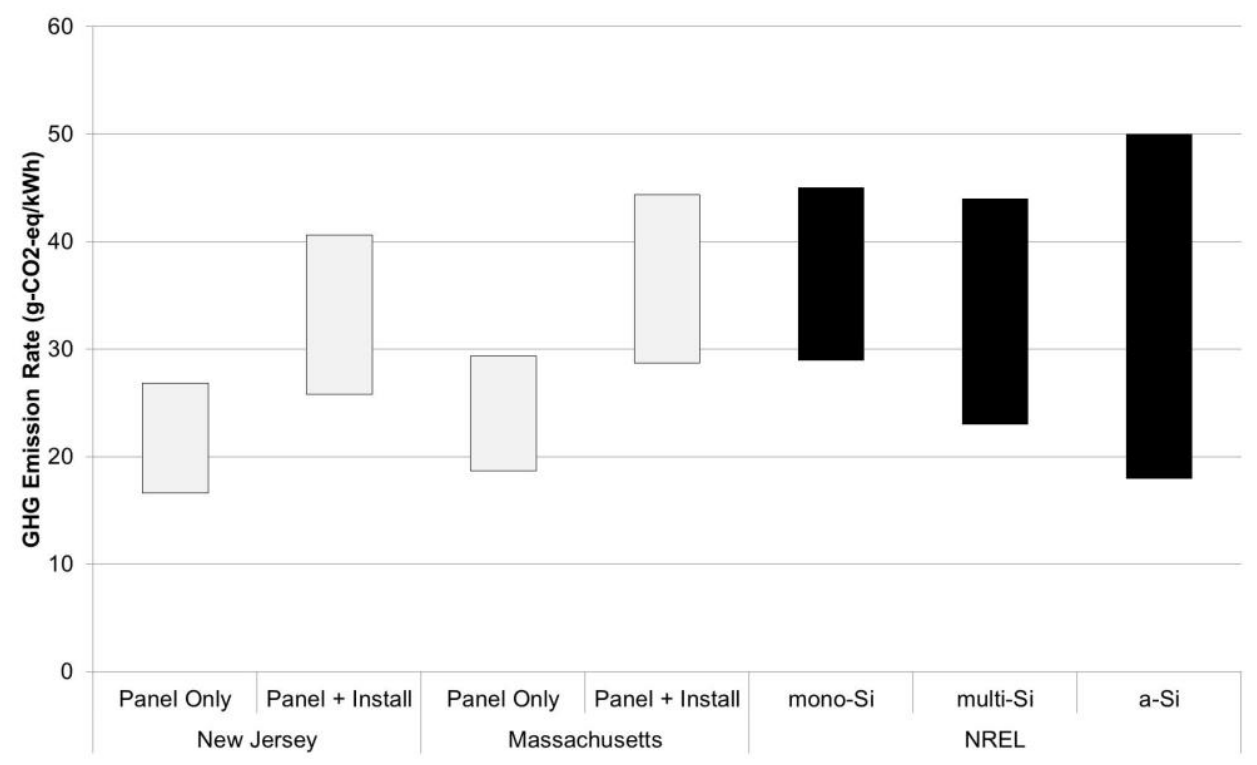

Figure OR3-2. Comparison of this study with NREL Solar Impact Analysis. The results of this study were adjusted from a 20 year lifetime to a 30 year lifetime in this comparison.

The assumptions made in this study generate greenhouse gas emission rates that are within the range of greenhouse gas emission rates presented for the three types of silicon solar panels presented in the NREL Solar Impact Analysis. The inclusion of installation impacts in this study results in higher greenhouse gas emissions rates when compared with the panel alone, but both are within the range of the NREL study. 


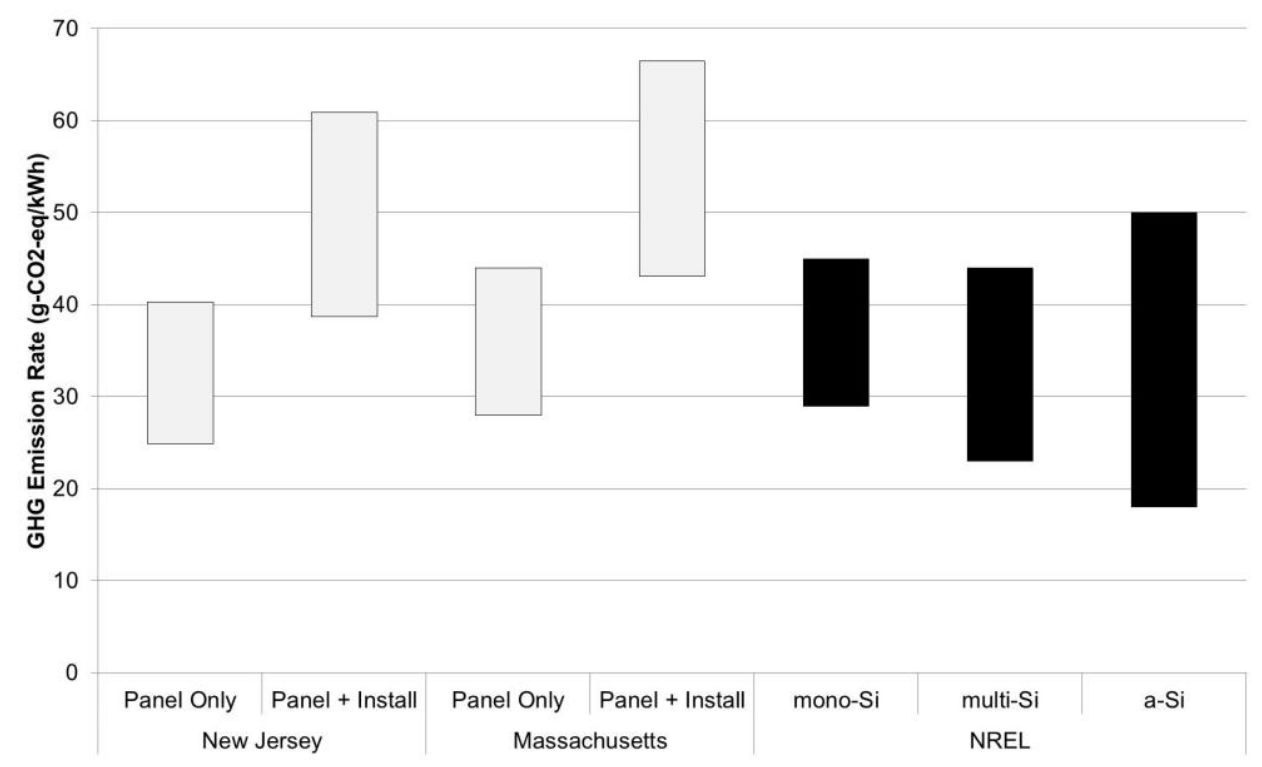

Figure OR3-3. Comparison of this study with NREL Solar Impact Analysis with 20 year lifetime assumption. Note that the assumed lifetime for the NREL Study is 30 years.

The assumption of a 20-year lifetime is a significant difference between our study and the NREL analysis, and leads to higher greenhouse gas emission rates. The 20 year lifetime was chosen to reflect conservation assumption of panel lifetime and also make a statement about the rapidly-changing nature of the technology. It is assumed that even if a panel could last for thirty years, the technology advances (in efficiency, for example) would make more frequent replacement a reasonable expectation. 


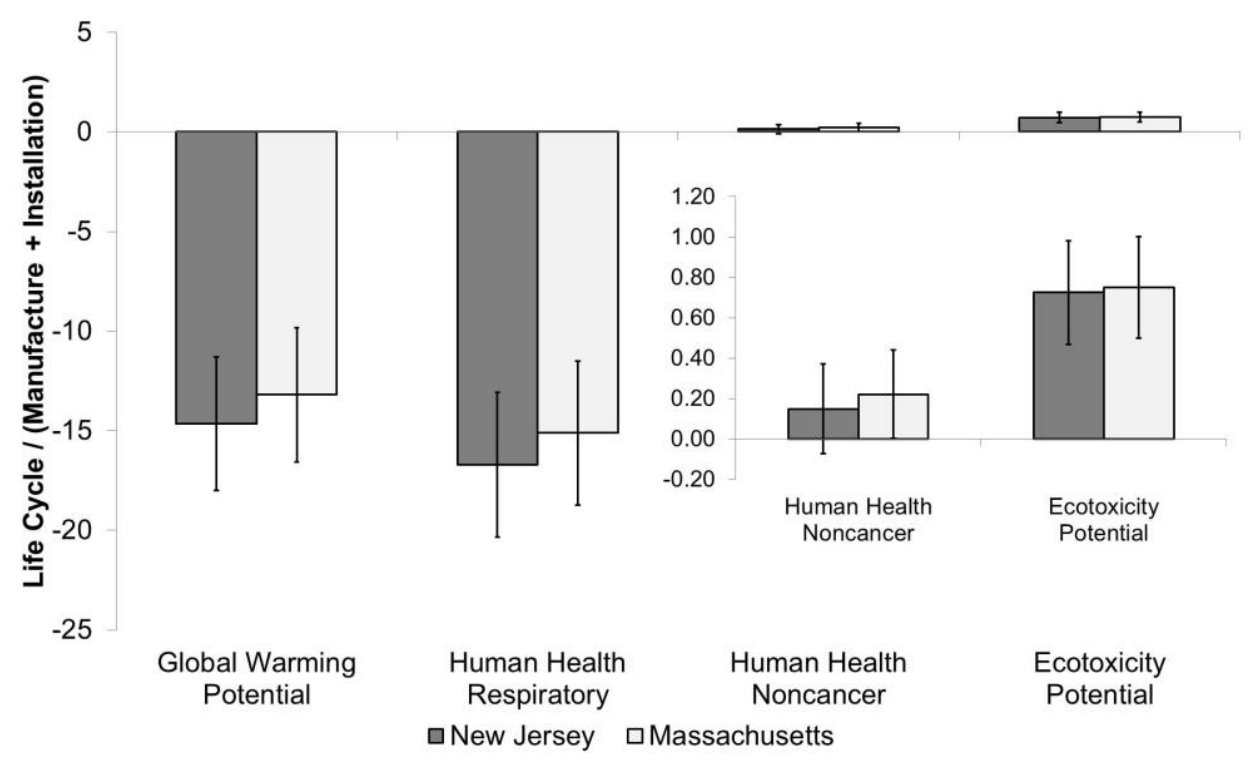

Figure OR3-4. Life cycle impacts for an average homeowner (MA $=6.02 \mathrm{~kW}, \mathrm{NJ}=8.18 \mathrm{~kW})$ assuming a 20 year panel lifetime. Error bars represented standard deviations from Monte Carlo analysis $(n=1000)$.

\section{Contribution analysis of solar panel ecotoxicity}

The manufacturing of solar panels was found to have a major influence on the life cycle impact assessment for the solar panels. A contribution analysis of the ecotoxicity potential shows that metals released in the mining and manufacturing processes are responsible for the majority of ecotoxicity impacts, as shown in the figure below.

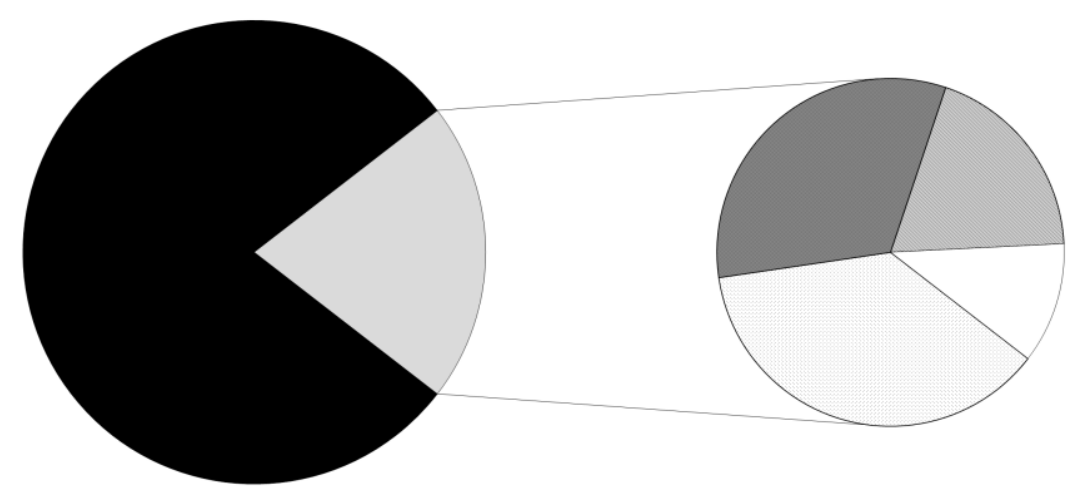

- Aluminum $\square$ Zinc $\square$ Copper $\square$ Nickel $\square$ All Other Compounds

Figure OR3-5. Contribution analysis of ecotoxicity for solar panel manufacture. 
5. Relative impact of different types of solar panels during production process

\begin{tabular}{|l|l|l|l|}
\hline \multicolumn{5}{|c|}{ Relative Impact per Square Meter } \\
\hline & Multi & Ribbon & Single \\
\hline $\begin{array}{l}\text { Global } \\
\text { Potential }\end{array}$ & 0.74 & 0.55 & 1.00 \\
\hline $\begin{array}{l}\text { Human Health } \\
\text { Cancer }\end{array}$ & 0.80 & 0.69 & 1.00 \\
\hline $\begin{array}{l}\text { Ecotoxicity } \\
\text { Potential }\end{array}$ & 0.64 & 0.58 & 1.00 \\
\hline
\end{tabular}

Figure OR3-6. Relative impact of different types of solar panels during production process. 